\title{
Metal ion remediation by polyamidoamine dendrimers: a comparison of metal ion, oxidation state, and titania immobilization
}

\author{
V. A. Castillo $\cdot$ M. A. Barakat $\cdot$ M. H. Ramadan • \\ H. L. Woodcock $\cdot$ J. N. Kuhn
}

Received: 1 January 2013/Revised: 9 April 2013/Accepted: 26 May 2013/Published online: 26 June 2013

(C) Islamic Azad University (IAU) 2013

\begin{abstract}
The exceptional ability of dendrimers to coordinate metal ions yields the potential for many applications including wastewater remediation, which is the focus of this study. Here, the comparison of metal ion removal rate from simulated wastewater by generation 4 dendrimers with external hydroxyl functional groups $(\mathrm{G} 4-\mathrm{OH})$ is evaluated for $\mathrm{Ni}^{2+}, \mathrm{Fe}^{2+}$, and $\mathrm{Fe}^{3+}$ ions. $\mathrm{Ni}^{2+}$ to amine complexation occurred more rapidly than $\mathrm{Fe}^{3+}$, which was more rapid than $\mathrm{Fe}^{2+}$ complexation. These results indicate that both charge density and d-electron configuration are important toward the chelation rate. The impact of both factors is discussed in light of existing models in which precursor aquation rates have been proposed as a key intermediate step. Additionally, the application of the dendrimers as chelation agents is further advanced by immobilizing the dendrimer to titania and re-evaluating its chelation ability for $\mathrm{Ni}^{2+}$ removal. The dendrimer immobilization decreased the pseudo-first-order rate coefficient for $\mathrm{Ni}^{2+}$-amine complexation at a $\mathrm{pH}$ of 7 by a factor of 7.5. This result is significant as it suggests that
\end{abstract}

V. A. Castillo · J. N. Kuhn $(\bowtie)$

Department of Chemical and Biomedical Engineering,

University of South Florida, 4202 East Fowler Avenue,

ENB 118, Tampa, FL 33620, USA

e-mail: jnkuhn@usf.edu

M. A. Barakat · M. H. Ramadan

Environmental Sciences Department, Faculty of Meteorology and Environment, King Abdulaziz University (KAU),

Jeddah, Saudi Arabia

M. A. Barakat

Central Metallurgical R\&D Institute, P. O. Box 87,

Helwan, Cairo 11421, Egypt

H. L. Woodcock

Department of Chemistry, University of South Florida,

Tampa, FL, USA mass transfer becomes important following immobilization of the dendrimer to titania.

Keywords Wastewater remediation - Polyamidoamine dendrimer $\cdot$ Iron $\cdot$ Nickel $\cdot$ Chelation

\section{Introduction}

The multifunctional nature of dendrimer macromolecules (Astruc et al. 2010; Lee et al. 2005; Myers et al. 2011; Tomalia et al. 1990) offers potential advancements for a number of technological applications including drug delivery (Esfand and Tomalia 2001; Kitchens and Ghandehari 2009), nanoparticle synthesis (Bronstein and Shifrina 2011; Kuhn et al. 2008; Witham et al. 2010; Yamamoto et al. 2010; Ye et al. 2007), and environmental remediation (Diallo et al. 1999, 2004, 2005; Xu and Zhao 2005). Dendrimers are specifically enticing for environmental purposes because of the high density of internal functional groups and the ability to alter the chemistry of the external functional groups. Several studies have focused on purification of metal ions in simulated wastewater using dendrimers in solution, and the relevant findings from these studies are now highlighted.

For Pt ion templating in a hydroxyl-terminated generation 4 PAMAM dendrimer $(\mathrm{G} 4-\mathrm{OH})$, the Crooks group correlated the maximum metal ion uptake amount to the number of internal tertiary amines (Zhao and Crooks 1999; Zhao et al. 1998). This conclusion was corroborated by an in-depth NMR study that showed innermost methylene groups as most sensitive to Pd ion chelation and concluded that the Pd was encapsulated within the dendrimer (Gomez et al. 2008). A variety of metal ions (e.g., Pt (Knecht et al. 2008a, b; Zhao and Crooks 1999), Pd (Gomez et al. 2008; 
Knecht et al. 2008a, b), Rh (Huang et al. 2008), Cu (Balogh and Tomalia 1998; Zhao et al. 1998), Ni (Castillo and Kuhn 2012; Gates et al. 2010; Knecht et al. 2006), Fe (Castillo and Kuhn 2012; Knecht and Crooks 2007), Au (Knecht et al. 2008a, b), and Sn (Gates et al. 2010) chelated by dendrimers for the purposes of nanoparticle synthesis illustrate the usefulness of applying dendrimers to water purification. Of those studies above that occurred in aqueous solutions, a wide variety of complexation times were required. These times varied from less than $1 \mathrm{~h}$ for Pd (Witham et al. 2010) to nearly 3 days for Pt (Huang et al. 2008). Although not all conditions of complexation were identical, the broad range of chelation times indicates the need for systematic studies on complexation rates if these materials are to be repurposed for the removal of wastewater contaminants.

Using $\mathrm{Fe}^{3+}$ as a model metal ion, a second-order rate expression (first order in dendrimer and first order in $\mathrm{Fe}$ when below the 1:1 metal ion-to-tertiary amine ratio) with an Arrhenius-type temperature dependence was proposed (Mankbadi et al. 2011). Although focused on the mechanism of Pt nanoparticle synthesis, two efforts (Knecht et al. 2008a, b; Yamamoto et al. 2011) are of particular importance to the present discussion. First, the Crooks group (Knecht et al. 2008a, b) showed that the chelation rate was limited by the ligand exchange kinetics of the Pt cation in solution between chlorides and water and decreased the time needed for chelation by presolvating the Pt precursor. To better quantify this process, Yamamoto et al. (2011) developed a detailed kinetic model describing Pt ion-ligand exchange and complexation of Pt with the tertiary amine functional group of the dendrimer. This work predicted that the metal ion coordination times correlate with precursor solvation kinetics.

In this contribution, the application of dendrimers toward environmental purification of metal ions from wastewater is rigorously assessed. Metal ion adsorption is evaluated for three metal ion species $\left(\mathrm{Ni}^{2+}, \mathrm{Fe}^{2+}\right.$, and $\left.\mathrm{Fe}^{3+}\right)$ in batch remediation studies. Results of this effort yield insight into the role of oxidation state and metal into the removal process and will be discussed in light of the proposed complexation trends and models in the literature (Yamamoto et al. 2011). Such information is needed as dendrimer-based chelation technology is applied to complex and real systems where multiple metal ions are present. Another focus of this effect is to assess dendrimer immobilization by metal oxides, a method to improve separation and reuse of the material, on the adsorption rate. Titania-immobilized dendrimers were recently surveyed (Barakat et al. 2013) for the removal of metal ions typically generated from the electroplating industry. Consequently, dendrimers were immobilized onto titania and applied toward $\mathrm{Ni}^{2+}$ removal. The role of metal ion, oxidation state, and dendrimer immobilization on metal oxides in the behaviors of the materials as applied to wastewater remediation by dendrimers is discussed based on these results.

\section{Materials and methods}

\section{Materials}

Generation 4 polyamidoamine (PAMAM) dendrimers (G4$\mathrm{OH}$ ) were purchased from Sigma-Aldrich (through Dendritech $^{\circledR}$, Inc. in Midland, MI) as a $10 \%$ (mass) solution with methanol as the solvent and used without further purification. $\mathrm{FeCl}_{3}, \mathrm{FeBr}_{2}$, and $\mathrm{NiCl}_{2}$ were of research grade and procured from Sigma-Aldrich. Titanium (IV) dioxide or titania (rutile, $99.5 \%$ purity, 1-2 micron particle size) was purchased from Alfa-Aesar. All other reagents were of analytical grade and supplied by Sigma-Aldrich or Merck.

Batch metal ion remediation studies monitored by UV-Vis spectroscopy

Metal ions $\left(\mathrm{Fe}^{3+}, \mathrm{Fe}^{2+}\right.$, or $\left.\mathrm{Ni}^{2+}\right)$ were each dissolved in DI water from the precursors mentioned in "Materials" section to $0.01 \mathrm{M}$ solution. A fresh solution was prepared for each experiment. An aliquot $(1.5 \mathrm{~mL})$ of this solution was mixed with $1.5 \mathrm{~mL}$ of a $250 \mu \mathrm{M}$ dendrimer stock solution prepared from the as-received solution and house DI water. The amount of metal ions per dendrimer was held constant at 40:1, and this ratio remained constant to ensure that all of the amine groups of the dendrimer were not saturated for any experiments. There was no $\mathrm{pH}$ change during the course of the experiments. The complexation reaction between the metal ions and the dendrimer was monitored by UV-Vis spectroscopy. Spectra were acquired with a NanoDropTM 1000 Spectrophotometer. A solution of G4$\mathrm{OH}$ of the same concentration used in the synthesis was used for background subtraction.

Batch remediation studies to monitor the removal of metal ions by dendrimer/titania composite materials

The dendrimer was added to titania in an aqueous slurry to achieve a dendrimer/titania adsorbent after sonication and drying. The complete synthesis of the dendrimer/titania composite was described in an earlier publication (Barakat et al. 2013). Infrared (FTIR) spectra of fresh and used composites were acquired with a PerkinElmer Spectrum 100 FTIR Spectrometer. Air was used for background subtraction. Separation of $\mathrm{Ni}^{2+}$ was performed in a wellmixed 500-mL conical flask at room temperature by combining an appropriate amount of $\mathrm{Ni}^{2+}$ metal ions with the dendrimer/titania adsorbent. The $\mathrm{pH}$ of the solutions was controlled by adding $1 \mathrm{M} \mathrm{HCl}$ or $1 \mathrm{M} \mathrm{NaOH}$ and monitored using an Orion $\mathrm{pH}$ meter. The $\mathrm{pH}$ was checked every 20 min and adjusted as needed. Metal ion concentrations were analyzed with an inductively coupled plasma (ICP) instrument as a function of time by removing $10-\mathrm{ml}$ 
aliquot of the resulting solution. Efficiency of metal ion removal was calculated with the following equation:

$\%$ Efficiency of metal removal $=\left(C_{\mathrm{o}}-C\right) / C_{\mathrm{o}} \times 100$

where $C_{\mathrm{o}}$ is the initial metal ion concentration and $C$ is the retained metal ion concentration. Control experiments confirmed that there was not any precipitation in the absence of an adsorbent.

Rate analyses

The transient curves obtained from the batch experiments are quantified using a pseudo-first-order rate expression. Previous work (Mankbadi et al. 2011) proposed a rate expression with a first-order dependency in metal ion concentration. In this paper, the initial dendrimer concentration was the same so it does not have an impact on the rate constants calculated from the pseudo-first-order rate expression.

\section{Results and discussion}

Batch metal ion remediation studies by dendrimers in aqueous solutions

The results of the batch metal ion removal studies on the dendrimers in aqueous solution are presented in Figs. 1, 2, and 3 for $\mathrm{Ni}^{2+}, \mathrm{Fe}^{2+}$, and $\mathrm{Fe}^{3+}$, respectively. These timeresolved UV-Vis spectra for $\mathrm{Fe}^{3+}$ were taken during the complexation processes to assess the rate of association between the metal ions and the dendrimer's internal tertiary amine groups. As discussed in the introduction, the Crooks group has previously demonstrated metal ion coordination by the internal tertiary amines (Gomez et al. 2008; Zhao and Crooks 1999; Zhao et al. 1998). For the metal ion complexation in Figs. 1, 2, and 3, the complexation process is monitored by the growth of bands associated with the ligandmetal charge transfer (LMCT). The LMCT is interpreted as a transfer of electrons from the HOMO of the tertiary amine to the metal center LUMO. Many researchers (Knecht et al. 2008a, b; Yamamoto et al. 2010, 2011; Zhao and Crooks 1999; Zhao et al. 1998) have identified this phenomenon as a method to demonstrate and track the complexation process. For the metal ions selected in this work, the LMCT bands largely appear in the $230-400 \mathrm{~nm}$ range of the UV-Vis spectra. Using a normalization procedure similar to that already developed (Yamamoto et al. 2011), the complexation rate coefficient was determined using pseudo-first-order kinetics (see Table 1). The comparison between experiment and modeling is presented in Fig. 4.

From this plot and the UV-Vis spectra in Figs. 1, 2, and 3, $\mathrm{Ni}^{2+}$ to amine complexation occurred more rapidly than

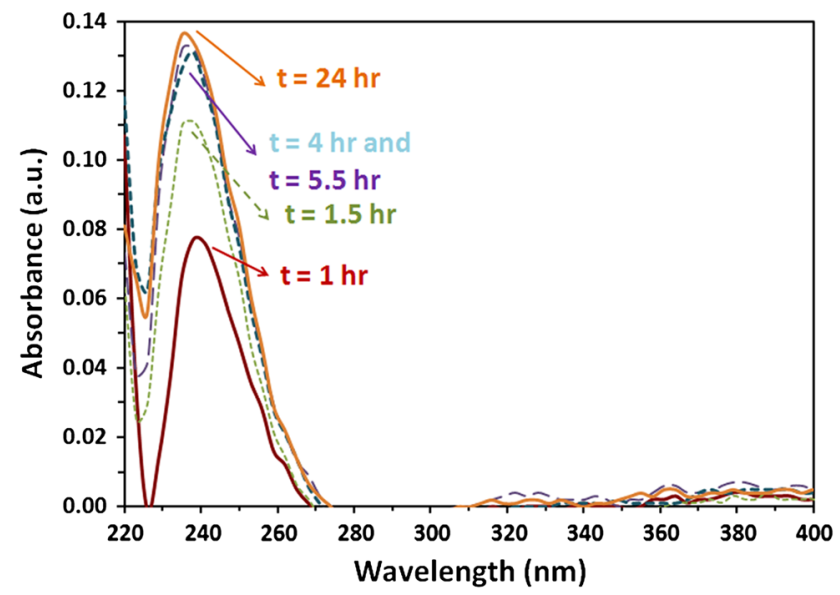

Fig. 1 Time-resolved UV-Vis spectra of $\mathrm{Ni}^{2+}$ coordination by amine groups of G4-OH PAMAM dendrimer. The band near $240 \mathrm{~nm}$ is indicative of ligand-metal charge transfer

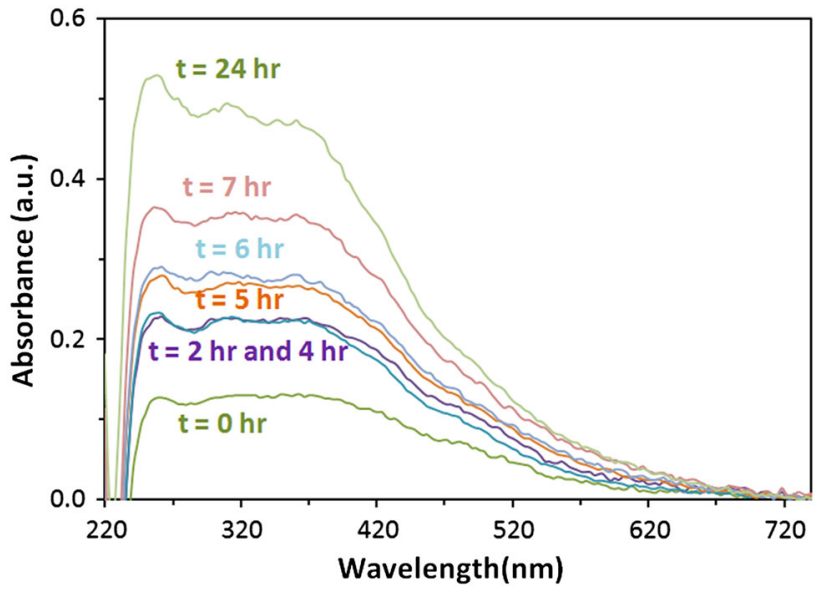

Fig. 2 Time-resolved UV-Vis spectra of $\mathrm{Fe}^{2+}$ coordination by amine groups of G4-OH PAMAM dendrimer. The band near $250 \mathrm{~nm}$ is indicative of ligand-metal charge transfer

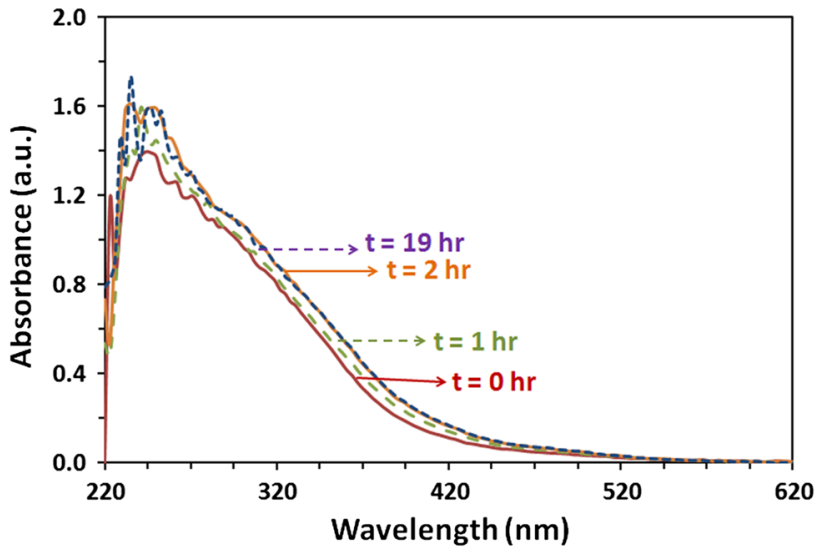

Fig. 3 Time-resolved UV-Vis spectra of $\mathrm{Fe}^{3+}$ coordination by amine groups of G4-OH PAMAM dendrimer. The band near $320 \mathrm{~nm}$ is indicative of ligand-metal charge transfer 
Table 1 Pseudo-first-order rate coefficients obtained at room temperature for various metal ions and dendrimer materials

\begin{tabular}{llllll}
\hline Entry & $\mathrm{pH}$ & Metal ion & {$\left[\mathrm{Me}^{+}\right], \mu \mathrm{mol} / \mathrm{L}$} & Dendrimer & $\mathrm{k}^{\prime}, \mathrm{h}^{-1}$ \\
\hline 1 & 7 & $\mathrm{Ni}^{2+}$ & 100 & Free & 0.905 \\
2 & 7 & $\mathrm{Fe}^{2+}$ & 100 & Free & 0.111 \\
3 & 7 & $\mathrm{Fe}^{3+}$ & 100 & Free & 0.360 \\
4 & 3 & $\mathrm{Ni}^{2+}$ & 430 & Immobilized & 0.047 \\
5 & 5 & $\mathrm{Ni}^{2+}$ & 430 & Immobilized & 0.049 \\
6 & 7 & $\mathrm{Ni}^{2+}$ & 430 & Immobilized & 0.120 \\
7 & 8 & $\mathrm{Ni}^{2+}$ & 430 & Immobilized & 0.260 \\
\hline
\end{tabular}

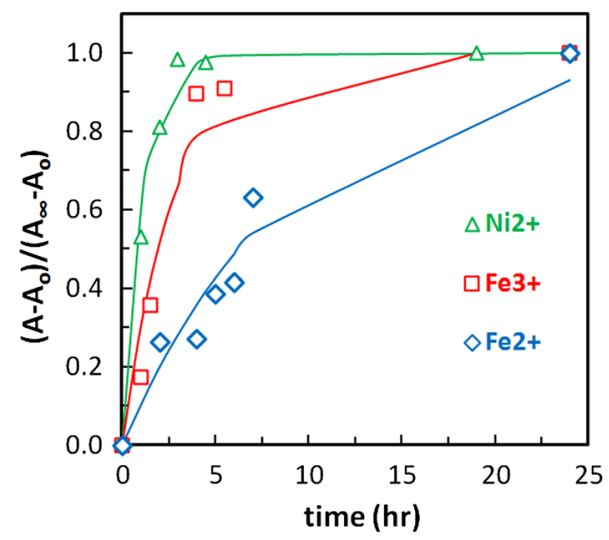

Fig. 4 Rate curves from normalized UV-Vis spectra for timeresolved results for $\mathrm{Ni}^{2+}, \mathrm{Fe}^{2+}$, and $\mathrm{Fe}^{3+}$

$\mathrm{Fe}^{3+}$, which was more rapid than $\mathrm{Fe}^{2+}$ complexation $\left(\mathrm{Ni}^{2+}>\mathrm{Fe}^{3+}>\mathrm{Fe}^{2+}\right)$. Spectra for all samples were constant beyond $24 \mathrm{~h}$. The normalization is necessary because not all LMCT effects have similar optical activity. The trend among metal ion-amine complexation was then compared to an existing model (Yamamoto et al. 2011) which proposed the ligand exchange of the precursor with water groups as the limiting step. The aquation rates for $\mathrm{Fe}^{3+}, \mathrm{Ni}^{2+}$, and $\mathrm{Fe}^{2+}$ metal ions are $1.6 \times 10^{2}, 2.5 \times 10^{4}$, and $2.5 \times 10^{6} \mathrm{~s}^{-1}$, respectively (Douglas et al. 1983). The relative rates between $\mathrm{Fe}^{3+}$ and $\mathrm{Ni}^{2+}$ follow the proposed (Yamamoto et al. 2011) trend, which is also in agreement with other ions [e.g., $\mathrm{Rh}^{3+}$ (Huang et al. 2008)] not included. However, chelation of $\mathrm{Fe}^{2+}$ and $\mathrm{Ni}^{2+}$ by the dendrimer does not follow that order. That is, the complexation of $\mathrm{Ni}^{2+}$ is more rapid than $\mathrm{Fe}^{2+}$ even though the aquation rate of $\mathrm{Fe}^{2+}$ is two orders of magnitude than the corresponding rate of $\mathrm{Ni}^{2+}$. All metal ions in this study required a longer complexation time than $\mathrm{Pd}^{2+}$ (Witham et al. 2010) even though the aquation rate of $\mathrm{Pd}^{2+}$ is on the same order of magnitude as $\mathrm{Ni}^{2+}$. Alternative to the aquation model, for the divalent species, the relative chelation rate follows the classical Irving-William series (i.e., $\mathrm{Ni}^{2+}>\mathrm{Fe}^{2+}$ ). Moreover, for the $\mathrm{Fe}^{\mathrm{x}+}$ species, the observation that the high-valence species complex more quickly than the low-valence one makes qualitative sense through the ability to accept more of the ligand's electron donation. These results demonstrate that the chemistry involved in the metal ion complexation process is more complicated than the aquation model proposed for Pt (Yamamoto et al. 2011) and cannot be extended to all metal ions. The complex chemistry associated with transition metals requires further examination (thermodynamic and kinetic) to understand and model the complexation process and the underlying d-electron configuration.

Regardless of the fundamental chemistry, assuming the simultaneous chelation of multiple metal ions does not impact the measured rate coefficients in Table 1 , the chelation selectivity of an equimolar mixture and examined conditions is predicted to be $26 \% \mathrm{Fe}^{3+}, 66 \% \mathrm{Ni}^{2+}$, and $8 \% \mathrm{Fe}^{2+}$. The simultaneous remediation of metal ion mixtures is currently under investigation.

Batch metal ion remediation studies by immobilized dendrimers

To facilitate the application of dendrimer remediation technology, the G4-OH dendrimer was grafted onto titania in a slurry process. Dendrimer immobilization is desired to enhance separation and regeneration. Titania was selected for several reasons including its common use in wastewater processing for photocatalysis so it is already proven as stable under relevant and similar conditions. Adsorption of metal laden dendrimers is commonly examined for loading of nanoparticles onto metal oxide supports (e.g., silica (Castillo and Kuhn 2012; Huang et al. 2008), alumina (Alexeev et al. 2006; Deutsch et al. 2007; Lopez-De Jesus et al. 2008), titania (Crump et al. 2008; Scott et al. 2005), and zirconia (Deutsch et al. 2007)) for the synthesis of heterogeneous catalysts. More in-depth studies also exist (Cahill et al. 2008). To confirm the immobilization, FTIR spectroscopy was performed onto the dendrimer/titania composite (Fig. 5).

The spectral features do not significantly change following the application of the composite materials as remediation agents for $\mathrm{Ni}^{2+}$. However, as will be discussed below, the dendrimer was shown to be stable on the titania. The bands associated with various dendrimer functional groups were analyzed via literature values (Deutsch et al. 2004, 2007; Ye et al. 2004). The respective bands at 2,972, 2,921, and $2,849 \mathrm{~cm}^{-1}$ match asymmetric $\mathrm{C}-\mathrm{H}$ methyl stretching, asymmetric $\mathrm{C}-\mathrm{H}$ methylene stretching, and symmetric $\mathrm{C}-\mathrm{H}$ methylene stretching. The respective bands at 1,648, 1,546, and $1,279 \mathrm{~cm}^{-1}$ confirm amide functionality through amide $\mathrm{C}=\mathrm{O}$ stretching, amide $\mathrm{C}-\mathrm{N}$ stretching and amide $\mathrm{C}-\mathrm{N}-\mathrm{H}$ bending/closing, and amide $\mathrm{C}-\mathrm{N}-\mathrm{H}$ bending/opening. The respective bands at $1,459,1,428$, and $1,349 \mathrm{~cm}^{-1}$ correspond to $\mathrm{H}-\mathrm{C}-\mathrm{H}$ scissoring, $\mathrm{H}-\mathrm{C}-\mathrm{H}$ asymmetric deformation, and $\mathrm{H}-\mathrm{C}-\mathrm{H}$ rocking, wagging, and twisting. Vibrational bands for the chemical linking of the organic dendrimer to titania 


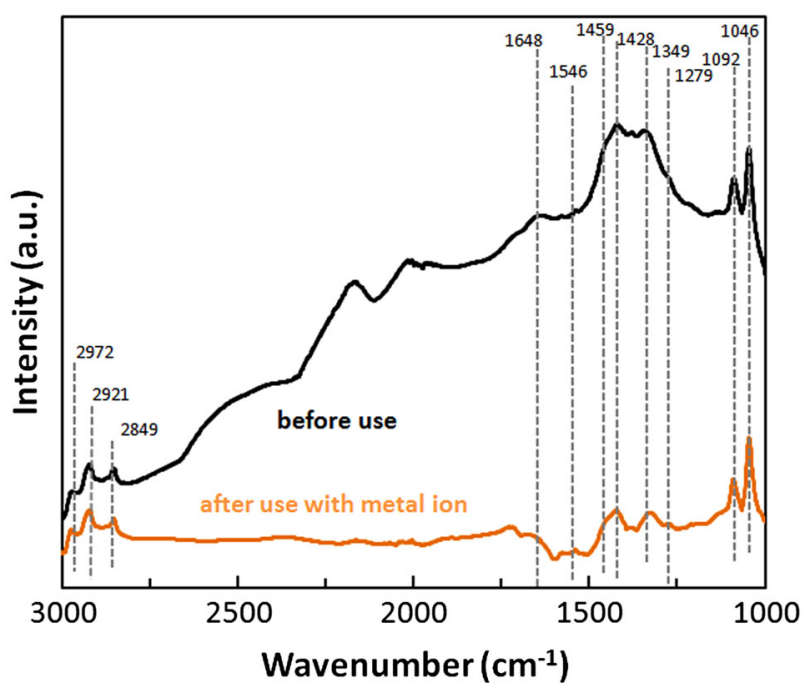

Fig. 5 FTIR spectroscopy before and after $\mathrm{Ni}^{2+}$ coordination for titania-immobilized G4-OH dendrimers

also exist. The bands at 1,092 and $1,046 \mathrm{~cm}^{-1}$ correspond to $\mathrm{Ti}-\mathrm{O}-\mathrm{C}$ bonds (Jensen et al. 2005). These bands infer a chemical interaction between the dendrimer and titania.

As part of a larger study (Barakat et al. 2013), the removal of $\mathrm{Ni}^{2+}$ ions was examined as a function of $\mathrm{pH}$ using the composite materials (highlighted in Fig. 6). The material's ability to remove $\mathrm{Ni}^{2+}$ ions increased with $\mathrm{pH}$. Control experiments were performed to show that $\mathrm{Ni}$ did not precipitate under these conditions. Using the same approach for kinetic modeling as already described, pseudo-first-order rate coefficients were calculated (Table 1) and increased with increasing $\mathrm{pH}$.

The internal tertiary amines of a G4-OH dendrimer have a pKa of 6.3 (Niu et al. 2003), which means that many of the amines are protonated under acid conditions (Sun and Crooks 2002). The results of Fig. 6 correspond well to those of the unprotonated fraction just mentioned. Comparing the rate coefficient of the $\mathrm{Ni}^{2+}$-amine complexation at a $\mathrm{pH}$ of 7 with and without the dendrimer being immobilized onto titania, the rate coefficient was a factor of 7.5 higher for the free $\mathrm{Ni}^{2+}$ dendrimer complex as compared to the titania-immobilized $\mathrm{Ni}^{2+}$-dendrimer complex. Potential explanations for this behavior include diffusional mass transfer limitations as the dendrimer may be contained within the titania's pores, a limited ability of the dendrimer to coordinate the metal ion because the binding to titania is limiting its flexibility, or a combination of both contributions. The coordination structures and rates with and without the dendrimer being bound to the titania is the current focus of research.

\section{Conclusion}

Metal ion removal rates from simulated wastewater by G4$\mathrm{OH}$ dendrimers were evaluated for $\mathrm{Ni}^{2+}, \mathrm{Fe}^{2+}$, and $\mathrm{Fe}^{3+}$.

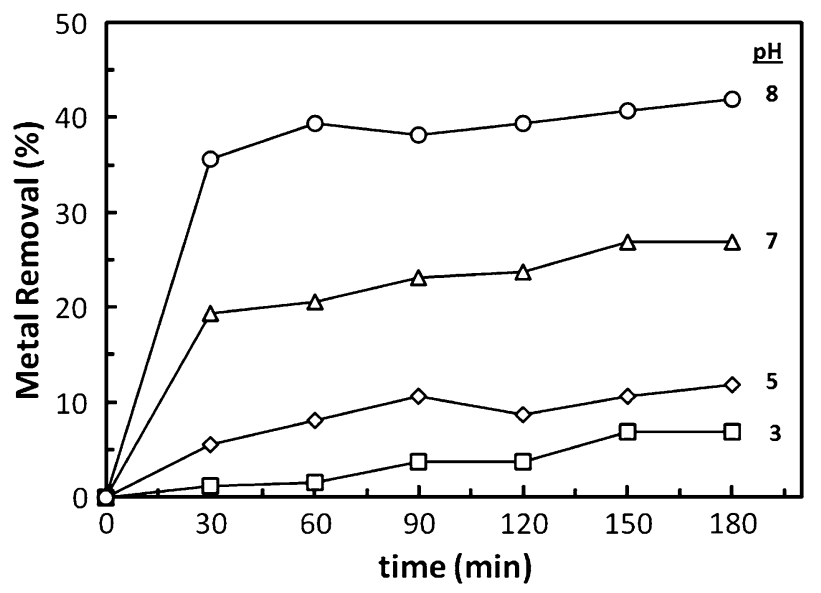

Fig. 6 Time-resolved UV-Vis spectra of $\mathrm{Ni}^{2+}$ coordination by titania-immobilized G4-OH dendrimers

The complexation of $\mathrm{Ni}^{2+}$ to internal tertiary amine sites occurred more rapidly than that of $\mathrm{Fe}^{3+}$, which was more rapid than $\mathrm{Fe}^{2+}$, thus indicating that both charge density and d-electron configuration are critical. The chelation ability of the dendrimer was also evaluated by immobilizing it onto titania for the removal of $\mathrm{Ni}^{2+}$ ions as a function of $\mathrm{pH}$. Pseudo-first-order rate coefficients were calculated, showing an increase correlated to increasing $\mathrm{pH}$. The trend $\mathrm{pH}$ occurs because the tertiary amines deprotonate under basic conditions, thus becoming sites for complexation. At a $\mathrm{pH}$ of 7 , the free dendrimer demonstrated a sevenfold better ability to complex $\mathrm{Ni}^{2+}$ from solution than the titaniaimmobilized dendrimer. The cause of this difference is most likely a combination of diffusional limitations due to the dendrimer now being within the titania's pores and decreased flexibility of the dendrimer, leading to limited restructuring to accommodate chelated metals.

Acknowledgments The authors gratefully acknowledge funding through a partnership with KAU under Grant number 2107105600. We thank the Florida Center of Excellence for Drug Discovery and Innovation for use facilities.

\section{References}

Alexeev OS, Siani A, Lafaye G, Williams CT, Ploehn HJ, Amiridis MD (2006) EXAFS characterization of dendrimer-Pt nanocomposites used for the preparation of $\mathrm{Pt} / \mathrm{ç}-\mathrm{Al} 2 \mathrm{O} 3$ catalysts. J Phys Chem B 110:24903-24914

Astruc D, Boisselier B, Ornelas C (2010) Dendrimers designed for functions: from physical, photophysical, and supramolecular properties to applications in sensing, catalysis, molecular electronics, photonics, and nanomedicine. Chem Rev 110:1857-1959

Balogh L, Tomalia DA (1998) Poly(amidoamine) dendrimer-templated nanocomposites. 1. Synthesis of zerovalent copper nanoclusters. J Am Chem Soc 20:7355-7356

Barakat MA, Ramadan MH, Al-Ghamdi M, Al-Garney S, Woodcock HL, Kuhn JN (2013) Remediation of $\mathrm{Cu}(\mathrm{II}), \mathrm{Ni}(\mathrm{II})$, and $\mathrm{Cr}(\mathrm{III})$ ions from simulated wastewater by dendrimer/titania composites. J Environ Manag 117:50-57 
Bronstein LM, Shifrina ZB (2011) Dendrimers as encapsulating, stabilizing, or directing agents for inorganic nanoparticles. Chem Rev 111:5301-5344

Cahill BP, Papastavrou G, Koper GJM, Borkovec M (2008) Adsorption of poly(amido amine) (PAMAM) dendrimers on silica: importance of electrostatic three-body attraction. Langmuir 24:465-473

Castillo VA, Kuhn JN (2012) Role of the Ni:Fe ratio in ethylene hydrogenation activity for silica-supported $\mathrm{Ni}-\mathrm{Fe}$ clusters prepared by dendrimer-templating. J Phys Chem C 116:8627-8633

Crump CJ, Gilbertson JD, Chandler BD (2008) CO oxidation and toluene hydrogenation by $\mathrm{Pt} / \mathrm{TiO} 2$ catalysts prepared from dendrimer encapsulated nanoparticle precursors. Top Catal 49:233-240

Deutsch DS, Lafaye G, Liu D, Chandler BD, Williams CT, Amiridis MD (2004) Decomposition and activation of Pt-dendrimer nanocomposites on a silica support. Catal Lett 97(3-4):139-143

Deutsch DS, Siani A, Fanson PT, Hirata H, Matsumoto S, Williams CT, Amiridis MD (2007) FT-IR investigation of the thermal decomposition of poly(amidoamine) dendrimers and dendrimermetal nanocomposites supported on $\mathrm{A} 12 \mathrm{O} 3$ and $\mathrm{ZrO} 2$. J Phys Chem C 111:4246-4255

Diallo MS, Balogh L, Shafagati A, Goddard WA III, Tomalia DA (1999) Poly(amidoamine) dendrimers: a new class of high capacity chelating agents for $\mathrm{Cu}(\mathrm{II})$ ions. Environ Sci Technol 33:820-824

Diallo MS, Christie S, Swaminathan P, Balogh L, Shi X, Um W, Papelis C, Goddard WA III, Johnson JH Jr (2004) Dendritic chelating agents. 1 . $\mathrm{Cu}$ (II) binding to ethylene diamine core poly(amidoamine) dendrimers in aqueous solutions. Langmuir 20:2640-2651

Diallo MS, Christie S, Swaminathan P, Johnson JH Jr, Goddard WA III (2005) Dendrimer enhanced ultrafiltration. 1. Recovery of $\mathrm{Cu}$ (II) from aqueous solutions using PAMAM dendrimers with ethylene diamine core and terminal $\mathrm{NH} 2$ groups. Environ Sci Technol 39:1366-1377

Douglas BE, McDaniel DH, Alexander JJ (1983) Concepts and models of inorganic chemistry, 2nd edn. Wiley, New York

Esfand R, Tomalia DA (2001) Poly(amidoamine) (PAMAM) dendrimers: from biomimicry to drug delivery and biomedical applications. Drug Discov Today 6:427-436

Gates AT, Nettleton EG, Myers VS, Crooks RM (2010) Synthesis and characterization of NiSn dendrimer-encapsulated nanoparticles. Langmuir 26:12994-12999

Gomez MV, Guerra J, Velders AH, Crooks RM (2008) NMR characterization of fourth-generation PAMAM dendrimers in the presence and absence of palladium dendrimer-encapsulated nanoparticles. J Am Chem Soc 131:341-350

Huang W, Kuhn JN, Tsung C-K, Zhang Y, Habas SE, Yang P, Somorjai GA (2008) Dendrimer templated synthesis of one nanometer $\mathrm{Rh}$ and $\mathrm{Pt}$ particles supported on mesoporous silica: catalytic activity for ethylene and pyrrole hydrogenation. Nano Lett 8(7):2027-2034

Jensen H, Soloviev A, Li Z, Søgaard EG (2005) XPS and FTIR investigation of the surface properties of different prepared titania nano-powders. Appl Surf Sci 246:239-249

Kitchens KM, Ghandehari H (2009) PAMAM dendrimers as nanoscale oral drug delivery systems. Nanotechnology in Drug Delivery, American Association of Pharmaceutical Scientists, New York, NY

Knecht MR, Crooks RM (2007) Magnetic properties of dendrimerencapsulated iron nanoparticles containing an average of 55 and 147 atoms. New J Chem 31:1349-1353

Knecht MR, Garcia-Martinez JC, Crooks RM (2006) Synthesis, characterization, and magnetic properties of dendrimer-Encapsulated nickel nanoparticles containing $<150$ atoms. Chem Mater 18:5039-5044

Knecht MR, Weir MG, Frenkel AI, Crooks RM (2008a) Structural rearrangement of bimetallic alloy $\mathrm{PdAu}$ nanoparticles within dendrimer templates to yield core/shell configurations. Chem Mater 20:1019-1028

Knecht MR, Weir MG, Myers VS, Pyrz WD, Ye H, Petkov V, Buttrey DJ, Frenkel AI, Crooks RM (2008b) Synthesis and characterization of Pt dendrimer-encapsulated nanoparticles: effect of the template on nanoparticle formation. Chem Mater 20:5218-5228

Kuhn JN, Huang W, Tsung C-K, Zhang Y, Somorjai GA (2008) Structure sensitivity of carbon-nitrogen ring opening: impact of platinum particle size from below 1 to $5 \mathrm{~nm}$ upon pyrrole hydrogenation product selectivity over monodisperse platinum nanoparticles loaded onto mesoporous silica. J Am Chem Soc 130:14026-14027

Lee CC, MacKay JA, Frechet JMJ, Szoka FC (2005) Designing dendrimers for biological applications. Nat Biotechnol 23: $1517-1526$

Lopez-De Jesus YM, Vicente A, Lafaye G, Marecot P, Williams CT (2008) Synthesis and characterization of dendrimer-derived supported iridium catalysts. J Phys Chem C 112:13837-13845

Mankbadi MR, Barakat MA, Ramadan MH, Woodcock HL, Kuhn JN (2011) Iron chelation by polyamidoamine dendrimers: a secondorder kinetic model for metal amine complexation. J Phys Chem B 115:13534-13540

Myers VS, Weir MG, Carino EV, Yancey DF, Pande S, Crooks RM (2011) Dendrimer-encapsulated nanoparticles: new synthetic and characterization methods and catalytic applications. Chem Sci 2:1632-1646

Niu Y, Sun L, Crooks RM (2003) Determination of the intrinsic proton binding constants for poly(amidoamine) dendrimers via potentiometric $\mathrm{pH}$ titration. Macromolecules 36:5725-5731

Scott RWJ, Sivadinarayana C, Wilson OM, Yan Z, Goodman DW, Crooks RM (2005) Titania-supported PdAu bimetallic catalysts prepared from dendrimer-encapsulated nanoparticle precursors. J Am Chem Soc 127(5):1380-1381

Sun L, Crooks RM (2002) Interactions between dendrimers and charged probe molecules. 1. Theoretical methods for simulating proton and metal ion binding to symmetric polydentate ligands. J Phys Chem B 106:5864-5872

Tomalia DA, Naylor AM, Goddard WA III (1990) Starburst dendrimers: molecular-level control of size, shape, surface chemistry, topology, and flexibility from atoms to macroscopic matter. Angew Chem Int Ed 29:138-175

Witham CA, Huang W, Tsung C-K, Kuhn JN, Somorjai GA, Toste FD (2010) Converting homogeneous to heterogeneous in electrophilic catalysis using monodisperse metal nanoparticles. Nat Chem 2:36-41

Xu Y, Zhao D (2005) Removal of copper from contaminated soil by use of poly(amidoamine) dendrimers. Environ Sci Technol 39:2369-2375

Yamamoto D, Watanabe S, Miyahara MT (2010) Coordination and reduction processes in the synthesis of dendrimer-encapsulated Pt nanoparticles. Langmuir 26:2339-2345

Yamamoto D, Watanabe S, Miyahara MT (2011) Modeling Pt2+ coordination process within poly(amidoamine) dendrimers for synthesis of dendrimer-encapsulated Pt nanoparticles. Ind Eng Chem Res 50:7332-7337

Ye H, Scott RWJ, Crooks RM (2004) Synthesis, characterization, and surface immobilization of platinum and palladium nanoparticles encapsulated within amine-terminated poly(amidoamine) dendrimers. Langmuir 20:2915-2920

Ye H, Crooks JA, Crooks RM (2007) Effect of particle size on the kinetics of the electrocatalytic oxygen reduction reaction catalyzed by $\mathrm{pt}$ dendrimer-encapsulated nanoparticles. Langmuir 23:11901-11906

Zhao M, Crooks RM (1999) Dendrimer-encapsulated Pt nanoparticles: synthesis, characterization, and applications to catalysis. Adv Mater 11:217-220

Zhao M, Sun L, Crooks RM (1998) Preparation of $\mathrm{Cu}$ nanoclusters within dendrimer templates. J Am Chem Soc 120:4877-4878 